\title{
Novel Approach to the Development of Functional Goat's Milk-Based Beverages Using Medicinal Plant Extracts in Combination with High Intensity Ultrasound Treatment
}

\author{
Draženka Komes*, Arijana Bušić, Ana Belščak-Cvitanović, Mladen Brnčić, Tomislav \\ Bosiljkov, Aleksandra Vojvodić and Filip Dujmić
}

University of Zagreb, Faculty of Food Technology and Biotechnology, Pierottijeva 6, HR-10000 Zagreb, Croatia

Received: December 22, 2016

Accepted: August 1, 2017

\begin{abstract}
Summary
Regardless of its highly valuable nutritive composition, goat's milk is less preferred by consumers due to its specific sensory characteristics that are very often regarded as undesirable. On the other hand, traditional medicinal plants from Lamiaceae family, due to their rich bioactive composition, especially polyphenols, and desirable aroma profile, can be used to enhance and improve bioactive and sensory properties of food. In the present study nutritively valuable beverages were produced by enrichment of goat's milk with medicinal plant extracts derived from the Lamiaceae family and stabilized by homogenization with high intensity ultrasound treatment. The impact of plant species (lemon balm, mint, lavender, rosemary and sage) and ultrasound treatment duration (5 or $10 \mathrm{~min}$ ) on the physicochemical, bioactive and sensory characteristics of enriched beverages was evaluated. The addition of plant extracts to goat's milk significantly increased the concentration of bioactive components (rosmarinic acid, hydroxycinnamic acid derivatives and luteolin derivatives), in dependence of the added plant extract. The prolongation of the ultrasound homogenization markedly decreased the fat globule size and thus beneficially affected the product stability. Apart from the achieved bioactive enrichment and stability, the developed beverages exhibited significantly improved sensory properties in comparison to plain goat's milk, with the highest overall acceptability determined for samples enriched with mint and rosemary.
\end{abstract}

Key words: goat's milk, medicinal plants, physicochemical properties, polyphenols, ultrasound homogenization

\section{Introduction}

During the last decade, increasing consumer awareness and better understanding of how food contributes directly to their health have considerably changed the consumer demands in the field of food production. These differences, deriving from a better knowledge of nutrition-health relation, resulted in the development of the functional food concept. Today it is well established that functional food products can be obtained by adding other functional ingredients to food, or by using processing and production methods that enable the preservation of na- tive active compounds in a specific product. In terms of employing the enrichment with or addition of other functional ingredients to a food product, most often medicinal plant extracts serve as the functional constituents, primarily due to their therapeutic effects, which are mostly attributed to the presence of polyphenolic compounds (1). Additionally, from the food industry aspect, plant extracts provide a reliable alternative to synthetic antioxidants that can prolong the storage stability and food preservation, mask undesirable flavours, and enhance sensory properties of food they are added to. Medicinal plants rep-

"Corresponding author: Phone: +385 14826 250; Fax: +385 14826 251; E-mail: dkomes@pbf.hr

ORCID IDs: 0000-0002-9062-1673 (Komes), 0000-0002-3572-5752 (Bušić), 0000-0003-4051-7912 (Belščak-Cvitanović), 0000-0002-8906-4291 (Brnčić), 0000-0001-6665-4208 (Bosiljkov), 0000-0002-8709-8068 (Vojvodić), 0000-0002-1615-3189 (Dujmić) 
resent an ideal substrate that can be successfully subjected to various preparation techniques, since they can be utilized in different forms such as fresh crude form, teas, decoctions or powdered plant material, and can therefore easily serve for tailoring novel food products.

From the aspect of production of functional food products by preservation of native active ingredients, in the food industry a special interest has arisen for tailoring new, safe and effective methods of food processing and preservation that in the end will result in high quality food products. Among alternative technologies that can contribute to retention of the quality level of various food products, high intensity ultrasound has become one of the most progressive technologies, used in various operations to accelerate mass transport processes, especially drying, mixing, homogenization, extraction and crystallization (2). Production of dairy products is one of the food processing areas where high intensity ultrasound already has its wide application, mostly for homogenization purposes. High intensity ultrasound implies frequencies in the range from 16 to $100 \mathrm{kHz}$, and 10 to $1000 \mathrm{~W} / \mathrm{cm}^{2}$ of power (3), which causes different physicochemical changes of the treated substrate (4).

Milk and milk products have always been considered as part of regular and balanced diet. During past years, goat's milk has received increasing attention due to its specific, but highly valuable nutritive composition, biological and therapeutic values. Improved digestibility, higher mineral composition quality, buffering capacity, higher therapeutic efficiency and many other characteristics are significantly differing goat's milk from other milk types (5). Today goat's milk is regarded as a high-quality raw material used for production of food for infants and the elderly, for population with certain medical problems, as well as for production of a wide range of other food products, including beverages (low fat, fortified, or flavoured) and UHT (ultra high temperature) milk, fermented products (cheese, buttermilk or yogurt), frozen products (ice cream or frozen yogurt), but also butter, condensed/dried products, sweets and candies (6). However, due to its distinctive and characteristic taste and flavour attributed to the presence of free short chain fatty acids, raw goat's milk is still very often unaccepted among a large number of consumers. Therefore, addition of medicinal plant extracts to goat's milk may contribute to the improvement of bioactive and sensory properties of this food substrate, while in combination with high intensity ultrasound treatment a complete development route of novel functional beverages may be defined. According to the authors' knowledge, the majority of studies dealing with the addition of polyphenolic plant extracts to dairy products are concentrated on functional fermented dairy products produced from cow's milk. Among them, the addition of catechin (7) and aloe vera $(8)$ to bifidobacteria-containing yogurt, flavonol-rich wine extract to milk and yogurt (9), green bell pepper juice to low fat fermented milk (10), and supplementation of yogurt with acidified ethanol extracts of four different grape varieties and grape callus (11) have been reported. Additionally, functional milk beverages fortified with phenolic compounds extracted from olive vegetable water and fermented with functional lactic acid bacteria were manufactured in a study of Servili et al. (12), while the effect of the addition of aqueous phenolic extracts from olive and grape pomace to fermentation media of the skimmed milk was investigated in a study of Aliakbarian et al. (13).

Therefore, the aim of this study is to prepare and utilize extracts of five traditional medicinal plants from Lamiaceae family (lemon balm, mint, lavender, rosemary and sage) for development of functional goat's milk-based beverages, with enhanced bioactive properties and improved sensory characteristics. Homogenization of enriched goat's milk was conducted by applying non-thermal high intensity ultrasound treatments during 5 and $10 \mathrm{~min}$. The effectiveness of this approach in the development of enriched functional goat's milk-based beverages was evaluated by screening their physicochemical parameters, bioactive profile and sensory characteristics.

\section{Materials and Methods}

\section{Chemicals}

Acetic acid, Folin-Ciocalteu, sodium carbonate, formaldehyde, hydrochloric acid, $n$-butanol, ammonium iron(II) sulfate dodecahydrate, formic acid, potassium acetate and potassium peroxodisulfate of analytical grade were supplied by Kemika (Zagreb, Croatia). Ethanol, sodium nitrite and sodium hydroxide were obtained from Gram-mol d.o.o. (Zagreb, Croatia), sodium acetate trihydrate was supplied from Alkaloid AD (Skopje, Macedonia), while nitric acid was from Carlo-Erba Reagents (Peypin, France). The 2,2-diphenyl-1-picrylhydrazyl (DPPH) was supplied by Fluka (Buchs, Switzerland). Vanillin, cyanidin chloride, 6-hydroxy-2,5,7,8-tetramethylchromane-2-carboxylic acid (Trolox), 2,2-azinobis(3-ethylbenzthiazoline-6-sulphonic acid) diammonium salt (ABTS), sodium molybdate, sodium carbonate decahydrate, casein, as well as gallic, tannic, rosmarinic, chlorogenic, caffeic and $p$-coumaric acids, catechin, luteolin, rutin and apigenin were obtained from Sigma-Aldrich (Steinheim, Germany). Methanol and acetonitrile (both HPLC grade) were supplied by J.T.Baker (Deventer, The Netherlands).

\section{Sample preparation}

\section{Preparation of plant extracts}

Dried plant materials of lemon balm (Melissa officinalis L.) leaves, mint (Mentha piperita L.) leaves, lavender (Lavandula angustifolia L.) flowers, rosemary (Rosmarinus officinalis L.) leaves and sage (Salvia officinalis L.) leaves were purchased in local herbal store Suban d.o.o. (Strmec Samoborski, Croatia). Extracts were prepared by pouring $200 \mathrm{~mL}$ of boiled distilled water over $10 \mathrm{~g}$ of plant, followed by continuous stirring for 30 min, without maintaining the water temperature. The obtained extracts were filtered through a tea strainer and after cooling to room temperature their bioactive composition was evaluated.

\section{Preparation and ultrasonic homogenization of goat's} milk enriched with plant extracts

Raw goat's milk was supplied from a local manufacturer from the Zagreb area (Croatia). Before the addition to goat's milk, previously prepared plant extracts were evaporated to $1 / 3$ of the initial volume. Concentrated extracts were added to goat's milk in $10 \%$ of total volume and 
stirred well. Samples were homogenized with an ultrasonic processor (UP $100 \mathrm{H}$; Hielscher, Teltow, Germany) with maximum nominal power of $100 \mathrm{~W}$, constant ultrasonic frequency of $30 \mathrm{kHz}$, amplitude of $60 \%$ with full cycle $(c=1)$ during whole treatment which lasted $5\left(\mathrm{H}_{5}\right)$ and $10\left(\mathrm{H}_{10}\right)$ min. Volume of the samples (at temperature of $20^{\circ} \mathrm{C}$ ) was $50 \mathrm{~mL}$ and the diameter of the cylindrical probe was $7 \mathrm{~mm}$. As a control, plain goat's milk samples (without the addition of plant extracts) were also subjected to high intensity ultrasound homogenization.

\section{Physicochemical characterization of goat's milk samples}

\section{Chemical characterization of goat's milk samples}

Defatted dry matter, protein and lactose contents and $\mathrm{pH}$ of the plain goat's milk and goat's milk enriched with plant extracts were evaluated using low intensity ultrasound analyser Lactoscan SA60 (Milkotronic Ltd, Nova Zagora, Bulgaria). The analysis is based on the passage of the ultrasound wave of low intensity through liquid medium, where the measured speed of the ultrasound, as a consequence of the flow between two sensors, is directly proportional to the values that define the chemical content of evaluated samples. The flow was achieved by peristaltic pump and the volume of analysed sample comprised $30 \mathrm{~mL}$. The analyses were performed in triplicate and the results are expressed as mean value \pm standard deviation (S.D.).

\section{Colour measurements}

The colour of goat's milk enriched with plant extracts was evaluated using a colorimeter CM-3500d (Konica Minolta, Tokyo, Japan), and the readings of $L^{*}$ (lightness), $a^{*}$ (redness) and $b^{*}$ (yellowness) parameters were recorded. For the analyses, enriched goat's milk samples were filled into adequate cuvettes, and three replicate measurements were performed. Results were presented as mean values with corresponding S.D. Total colour difference $(\Delta E)$ was calculated according to the following equation (14):

$$
\Delta E=\sqrt{\left(L^{*}{ }_{0}-L^{*}\right)^{2}+\left(a^{*}{ }_{0}-a^{*}\right)^{2}+\left(b^{*}{ }_{0}-b^{*}\right)^{2}}
$$

where the subscript 0 refers to the colour value of plain goat's milk, representing reference sample.

\section{Fat globule size distribution}

Fat globule distribution of enriched samples was measured by light scattering using Mastersizer 2000 (Malvern Instruments, Malvern, UK), equipped with the Hydro $2000 \mathrm{~S}$ dispersion unit. Fat globule size distribution was expressed through $d(0.5)$ values, which represent median diameter, with $50 \%$ higher and $50 \%$ lower volume distribution from the observed diameter. Measurements were made in triplicate and the results are expressed as mean value \pm S.D.

\section{Phytochemical screening of evaluated plant extracts and enriched goat's milk samples}

Fibre content of evaluated plants

The content of soluble polysaccharides was determined according to a modified method of Wei et al. (15), based on the aqueous extraction of polysaccharides and their precipitation with ethanol. The analysis was performed in triplicate. The polysaccharide yield was calculated as the polysaccharide content of the extract divided by initial sample mass and expressed as percentage of dry mass \pm S.D.

Cellulose determination is based on plant deterioration by adding nitric and acetic acid, where the remaining residue represents cellulose (16). The analysis was performed three times and the cellulose yield was calculated as the ratio of dried hydrolyzed sample and initial sample mass, expressed as percentage of dry mass \pm S.D.

\section{Determination of polyphenolic compounds}

The obtained plant extracts were screened spectrophotometrically to determine their total polyphenolic and total flavonoid, hydroxycinnamic acid, proanthocyanidin, total tannin and flavan-3-ol contents using UV-Vis spectrophotometer (Helios $\gamma$; ThermoSpectronic, Cambridge, UK). Enriched goat's milk samples were assayed for total polyphenol and flavonoid contents after methanol precipitation to eliminate proteins from goat's milk and obtain adequate samples.

Total polyphenolic (TP) content was analysed using Folin-Ciocalteu reagent, according to a modified method of Lachman et al. (17). Based on the formaldehyde precipitation of flavonoids, total flavonoid (TF) content was calculated as the difference between total polyphenolic and nonflavonoid contents. Both results were expressed in $\mathrm{mg}$ of gallic acid equivalents (GAE) per L. Method for determination of hydroxycinnamic acids ( $\mathrm{mg}$ of caffeic acid equivalents (CAE) per L) was adapted from Matkowski et al. (18). Proanthocyanidins (i.e. condensed tannins) were analysed by the procedure described by Porter et al. (19) and expressed in $\mathrm{mg}$ of cyanidin chloride equivalents $(\mathrm{CyE})$ per $\mathrm{L}$. The content of total tannins was determined using casein as an adsorbing agent for tannins according to the modified method of Rusak et al. (20) and the results were expressed in mg of tannic acid equivalents (TAE) per L. Flavan-3-ol content was analysed using vanillin assay (21) and expressed in $\mathrm{mg}$ of $(+)$-catechin equivalents (CE) per L. All measurements were performed in triplicate, and the results are expressed as mean values \pm S.D.

\section{Determination of antioxidant capacity}

The antioxidant capacity of both plant extracts and enriched goat's milk samples (after methanol precipitation) was examined by two radical scavenging assays, ABTS and DPPH. The Trolox equivalent antioxidant capacity (TEAC) was estimated by the ABTS radical cation decolourization assay (22). Antioxidant capacity evaluated using the DPPH radical scavenging assay was described by Brand-Williams et al. (23). The results obtained from triplicate analyses were expressed in mmol of Trolox equivalents (TE) per L.

\section{HPLC analysis of polyphenolic compounds}

Before HPLC analysis, plant extracts and enriched goat's milk samples (after methanol precipitation) were filtered through 0.45- $\mu \mathrm{m}$ filter (Nylon Membranes, Supelco, Bellefonte, PA, USA). A sample $(20 \mu \mathrm{L})$ was injected using an Infinity Agilent 1100/1200 Series HPLC device (Agilent, Santa Clara, CA, USA) and a Photodiode Array Detector (Agilent) 
with a reversed-phase Zorbax extended C-18 column (250 $\mathrm{mm} \times 4.6 \mathrm{~mm}, 5 \mu \mathrm{m}$ i.d.; Agilent). The solvents consisted of $2 \%$ formic acid in water (solvent $\mathrm{A}$ ) and $2 \%$ formic acid in acetonitrile (solvent B) at a flow rate of $1 \mathrm{~mL} / \mathrm{min}$. The elution was gradient, starting at $90 \%$ A to $60 \%$ A after 25 min, then to $30 \% \mathrm{~A}$ for $45 \mathrm{~min}$ and in the end becoming isocratic for $5 \mathrm{~min}$. Chromatograms were recorded at $278 \mathrm{~nm}$, while detection was performed with a Photodiode Array Detector by scanning between 200 and $400 \mathrm{~nm}$, with a resolution of $1.2 \mathrm{~nm}$. Individual polyphenolics were identified by comparing the retention times and spectral data with those of standards. Analyses were performed in triplicate and the results are expressed in $\mathrm{mg}$ of compound per $\mathrm{L}$.

\section{Sensory evaluation of prepared plant extracts and enriched goat's milk samples}

Sensory properties of aqueous plant extracts and unhomogenized goat's milk samples enriched with plant extracts were evaluated using descriptive quantitative analysis. Before adding extracts to unhomogenized goat's milk samples, the milk was shortly heated to simulate pasteurization conditions $\left(72^{\circ} \mathrm{C}, 30 \mathrm{~s}\right)$. Plain goat's milk was used as control for enriched goat's milk samples.

Sensory panel of 15 people ( 9 female and 6 male) was comprised of internal sensory panel of the Faculty of Food Technology and Biotechnology (Zagreb, Croatia), varying in age from 25 to 45 . The panel confirmed the absence of aversions, allergies or intolerance to milk and evaluated plants; they were non-smokers, with normal perception abilities and previous experience in testing. Firstly, brief introduction into the methodology was given to the panellists, followed by discussion and clarification of particular attribute definitions. After description of sensory characteristics of each evaluated sample, and after discussion among panellists, main attributes for sensory evaluation were chosen. Five attributes (flavour, bitterness, astringency, sweetness and overall acceptability) of plant extracts were evaluated. Equal attributes, with the addition of aroma familiarity and colour of enriched goat's milk samples were assessed. Samples were scored on a 5-point intensity scale, where 5 marked strongly expressed characteristics and 1 poorly expressed characteristics. Moreover, an importance factor $(\mathrm{IF}=0.5-2)$ was ascribed to each attribute, where higher IF implied more important attribute. $\mathrm{IF}=2$ was assigned to flavour, overall acceptability and aroma familiarity, IF $=1.5$ was used for sweetness, IF $=1$ for bitterness and astringency, and IF $=0.5$ for the colour. The number of points describing each attribute was multiplied with the importance factor and the average point number was calculated. Warm water was provided for mouth rinsing between each sample.

\section{Statistical analysis}

The results were analysed statistically using the STATISTICA 7.0 software (24) to determine the average values and standard errors. One-way ANOVA, using the Tukey's post hoc test, with a significance level of $\mathrm{p}=0.05 \%$ was performed to determine the influence of the addition of different plant extracts to goat's milk samples and homogenization (treatment duration of 5 and $10 \mathrm{~min}$ ) on evaluated parameters. The same statistical analysis was also used to explore the differences among plant extracts and to evaluate the influence of the addition of plant extracts to goat's milk on the investigated sensory attributes. The probability level of $\mathrm{p}<0.05$ was considered as significant.

\section{Results and Discussion}

\section{Physicochemical characteristics of enriched goat's milk}

High intensity ultrasound treatments proved to be an effective homogenization technique with the aim of increasing stability and durability of different types of milk. As a consequence of propagation of ultrasound waves, high intensity ultrasound treatments very often lead to various physical and chemical changes of treated products. Therefore, the impact of high intensity ultrasound homogenization on the physicochemical changes of plain and enriched goat's milk samples was evaluated and displayed in Table 1.

By adding $10 \%$ of aqueous extracts to goat's milk, enriched goat's milk samples were diluted in certain amount, thus decreasing the defatted dry matter (DDM); however, not in a significant manner $(\mathrm{p}>0.05)$ when compared to plain goat's milk. After homogenization, again a decreasing pattern of DDM was observed, regardless of the ultrasound treatment duration. Longer homogenization time (10 min) resulted in insignificantly ( $>>0.05)$ lower DDM than in unhomogenized goat's milk samples and samples homogenized for 5 min (Table 1).

With regard to protein content, unhomogenized plain goat's milk was characterized with $3.16 \%$ of proteins, whose content was slightly reduced after homogenization. Generally, the content of proteins decreased after the addition of plant extracts to goat's milk (Table 1), while the ultrasound homogenization exhibited no significant $(\mathrm{p}>0.05)$ influence on the protein content of enriched goat's milk samples.

A similar trend was observed for lactose, whose content in the unhomogenized plain goat's milk exhibited 4.75 $\%$, but decreased (although not significantly) after the addition of plant extracts to goat's milk. As can be seen in Table 1, ultrasound treatments, regardless of their duration, reduced the lactose content in all evaluated samples; however, without significant impact $(\mathrm{p}>0.05)$ when compared to their corresponding unhomogenized enriched goat's milk counterparts.

The statistical analysis revealed no significant impact ( $p>0.05$ ) of all evaluated parameters (plant extract or homogenization time) on the $\mathrm{pH}$ values of either enriched or treated goat's milk samples in comparison to unhomogenized goat's milk.

Colour measurements of $L^{*}, a^{*}, b^{*}$ values and total colour difference $(\Delta E)$ of plain and enriched goat's milk samples obtained from the experimental data indicated more pronounced differences in the colour of goat's milk samples (Table 1). Plain goat's milk samples had the highest $L^{*}$ values (lightness). Application of ultrasound decreased its $L^{*}$ values, indicating decreased lightness, and thus the appearance of darker colour after homogenization, which was more pronounced after longer treatment. As expected, the lightness was significantly decreased $(\mathrm{p}<0.05)$ after the addition of plant extracts to goat's milk, due to the naturally 
Table 1. Physicochemical parameters of plain and goat's milk enriched with plant extracts prior to (unhomogenized) and after ultrasound homogenization

\begin{tabular}{|c|c|c|c|c|c|c|c|c|c|}
\hline \multirow{2}{*}{ Sample } & \multicolumn{3}{|c|}{$w / \%$} & \multirow{2}{*}{$\mathrm{pH}$} & \multirow{2}{*}{$L^{*}$} & \multirow{2}{*}{$a^{*}$} & \multirow{2}{*}{$b^{*}$} & \multirow{2}{*}{$\Delta E$} & \multirow{2}{*}{$d(0.5) / \mu \mathrm{m}$} \\
\hline & $\begin{array}{l}\text { Defatted dry } \\
\text { matter }\end{array}$ & Proteins & Lactose & & & & & & \\
\hline \multicolumn{10}{|c|}{ Plain GM } \\
\hline $\mathrm{UH}$ & $8.64 \pm 0.10$ & $3.16 \pm 0.04$ & $4.75 \pm 0.05$ & $6.60 \pm 0.11$ & $18.16 \pm 0.07$ & $4.93 \pm 0.01$ & $28.86 \pm 1.00$ & - & $3.11 \pm 0.01$ \\
\hline $\mathrm{H}_{5}$ & $8.59 \pm 0.00$ & $3.14 \pm 0.00$ & $4.72 \pm 0.00$ & $6.81 \pm 0.05$ & $15.97 \pm 0.02$ & $5.23 \pm 0.02$ & $25.98 \pm 0.08$ & $4.14 \pm 0.01$ & $1.96 \pm 0.02$ \\
\hline $\mathrm{H}_{10}$ & $8.37 \pm 0.01$ & $3.06 \pm 0.00$ & $4.60 \pm 0.00$ & $6.68 \pm 0.02$ & $13.89 \pm 0.00$ & $5.88 \pm 0.01$ & $22.77 \pm 0.02$ & $8.02 \pm 0.01$ & $0.73 \pm 0.01$ \\
\hline \multicolumn{10}{|c|}{$\mathrm{GM}+\mathrm{LB}$} \\
\hline $\mathrm{UH}$ & $8.13 \pm 0.01$ & $2.98 \pm 0.01$ & $4.47 \pm 0.01$ & $6.80 \pm 0.04$ & $2.06 \pm 0.01$ & $6.24 \pm 0.03$ & $3.52 \pm 0.01$ & $30.57 \pm 0.10$ & $3.14 \pm 0.03$ \\
\hline $\mathrm{H}_{5}$ & $8.02 \pm 0.01$ & $2.94 \pm 0.01$ & $4.41 \pm 0.01$ & $6.77 \pm 0.01$ & $1.45 \pm 0.01$ & $4.76 \pm 0.02$ & $2.48 \pm 0.01$ & $31.73 \pm 0.10$ & $1.94 \pm 0.00$ \\
\hline $\mathrm{H}_{10}$ & $7.77 \pm 0.02$ & $2.84 \pm 0.01$ & $4.27 \pm 0.01$ & $6.66 \pm 0.02$ & $0.98 \pm 0.04$ & $3.29 \pm 0.00$ & $1.58 \pm 0.01$ & $32.78 \pm 0.05$ & $0.72 \pm 0.01$ \\
\hline \multicolumn{10}{|c|}{$\mathrm{GM}+\mathrm{M}$} \\
\hline $\mathrm{UH}$ & $8.44 \pm 0.01$ & $3.08 \pm 0.00$ & $4.64 \pm 0.01$ & $6.52 \pm 0.01$ & $1.93 \pm 0.04$ & $5.93 \pm 0.04$ & $3.28 \pm 0.02$ & $30.83 \pm 0.02$ & $3.31 \pm 0.03$ \\
\hline $\mathrm{H}_{5}$ & $8.29 \pm 0.01$ & $3.04 \pm 0.01$ & $4.56 \pm 0.01$ & $6.52 \pm 0.01$ & $1.80 \pm 0.03$ & $5.69 \pm 0.01$ & $3.10 \pm 0.01$ & $31.04 \pm 0.02$ & $2.38 \pm 0.01$ \\
\hline $\mathrm{H}_{10}$ & $8.13 \pm 0.03$ & $2.97 \pm 0.10$ & $4.47 \pm 0.02$ & $6.57 \pm 0.05$ & $1.62 \pm 0.01$ & $5.17 \pm 0.01$ & $2.71 \pm 0.01$ & $31.45 \pm 0.01$ & $1.03 \pm 0.00$ \\
\hline \multicolumn{10}{|c|}{$\mathrm{GM}+\mathrm{L}$} \\
\hline $\mathrm{UH}$ & $8.27 \pm 0.03$ & $3.02 \pm 0.01$ & $4.55 \pm 0.02$ & $6.80 \pm 0.10$ & $4.22 \pm 0.11$ & $8.85 \pm 0.05$ & $7.14 \pm 0.04$ & $26.63 \pm 0.01$ & $3.25 \pm 0.01$ \\
\hline $\mathrm{H}_{5}$ & $8.12 \pm 0.01$ & $2.97 \pm 0.01$ & $4.46 \pm 0.00$ & $6.76 \pm 0.03$ & $3.12 \pm 0.03$ & $7.07 \pm 0.04$ & $5.32 \pm 0.01$ & $28.53 \pm 0.00$ & $2.02 \pm 0.02$ \\
\hline $\mathrm{H}_{10}$ & $7.90 \pm 0.01$ & $2.89 \pm 0.00$ & $4.34 \pm 0.00$ & $6.61 \pm 0.02$ & $2.24 \pm 0.01$ & $5.90 \pm 0.04$ & $3.75 \pm 0.00$ & $30.26 \pm 0.01$ & $0.83 \pm 0.02$ \\
\hline \multicolumn{10}{|c|}{$\mathrm{GM}+\mathrm{R}$} \\
\hline $\mathrm{UH}$ & $8.05 \pm 0.02$ & $2.95 \pm 0.01$ & $4.42 \pm 0.01$ & $6.68 \pm 0.01$ & $8.90 \pm 0.02$ & $11.78 \pm 0.00$ & $15.03 \pm 0.01$ & $18.52 \pm 0.04$ & $3.01 \pm 0.00$ \\
\hline $\mathrm{H}_{5}$ & $7.92 \pm 0.12$ & $2.90 \pm 0.00$ & $4.35 \pm 0.00$ & $6.67 \pm 0.01$ & $7.25 \pm 0.00$ & $11.57 \pm 0.01$ & $12.28 \pm 0.02$ & $21.46 \pm 0.01$ & $1.94 \pm 0.00$ \\
\hline $\mathrm{H}_{10}$ & $7.78 \pm 0.01$ & $2.84 \pm 0.00$ & $4.27 \pm 0.00$ & $6.62 \pm 0.01$ & $5.10 \pm 0.04$ & $9.96 \pm 0.01$ & $8.60 \pm 0.01$ & $25.15 \pm 0.01$ & $1.11 \pm 0.03$ \\
\hline \multicolumn{10}{|c|}{$\mathrm{GM}+\mathrm{S}$} \\
\hline $\mathrm{UH}$ & $8.20 \pm 0.01$ & $3.00 \pm 0.01$ & $4.51 \pm 0.01$ & $6.70 \pm 0.01$ & $1.73 \pm 0.01$ & $5.53 \pm 0.02$ & $2.91 \pm 0.01$ & $31.24 \pm 0.01$ & $3.03 \pm 0.02$ \\
\hline $\mathrm{H}_{5}$ & $8.16 \pm 0.00$ & $2.98 \pm 0.00$ & $4.48 \pm 0.00$ & $6.56 \pm 0.04$ & $1.50 \pm 0.00$ & $5.07 \pm 0.01$ & $2.59 \pm 0.01$ & $31.62 \pm 0.06$ & $2.25 \pm 0.07$ \\
\hline $\mathrm{H}_{10}$ & $7.93 \pm 0.01$ & $2.90 \pm 0.00$ & $4.36 \pm 0.01$ & $6.64 \pm 0.01$ & $1.09 \pm 0.00$ & $3.81 \pm 0.02$ & $1.88 \pm 0.00$ & $32.45 \pm 0.01$ & $1.15 \pm 0.01$ \\
\hline
\end{tabular}

Values are expressed as mean \pm standard deviation $(N=3)$. GM=goat's milk, $G M+L B=G M$ enriched with lemon balm extract, $G M+M=G M$ enriched with mint extract, $G M+L=G M$ enriched with lavender extract, $G M+R=G M$ enriched with rosemary extract, $G M+S=G M$ enriched with sage extract, $\mathrm{UH}=$ unhomogenized samples, $\mathrm{H}_{5}=$ samples homogenized for $5 \mathrm{~min}, \mathrm{H}_{10}=$ samples homogenized for $10 \mathrm{~min}, \Delta E=$ total colour difference

present pigments in plant extracts, mostly chlorophylls. Among enriched samples, the lowest $L^{*}$ value was observed after the addition of sage extract $\left(L^{*}=1.73\right)$, while the addition of rosemary resulted in the brightest sample $\left(L^{*}=8.90\right)$, which provided significantly $(\mathrm{p}<0.05)$ higher $L^{*}$ values than others. Positive $a^{*}$ and $b^{*}$ colour values of enriched goat's milk corresponded to red and yellow colours that prevailed upon the addition of plant extract to the milk. Enriched unhomogenized samples showed increased $a^{*}$ values in comparison with plain unhomogenized goat's milk, especially with milk samples enriched with lavender and rosemary extracts, where significant differences were observed $(\mathrm{p}<0.05)$ when compared to goat's milk. On the contrary, $b^{*}$ colour values exhibited a decreasing pattern after the addition of plant extracts and after ultrasound treatments. The decrease of $b^{*}$ values upon the addition of plant extracts indicated a shift of the obtained goat's milk beverages towards green colour. In the case of both $a^{*}$ and $b^{*}$ colour values, ultrasound homogenization resulted in a decrease of these values in comparison with unhomogenized beverages, with more prominent decrease after $10 \mathrm{~min}$. Due to the pigment abundance in plant extracts, total colour difference $(\Delta E)$ was markedly affected by the addition of plant extracts to goat's milk, exhibiting significant $(\mathrm{p}<0.05)$ differences when compared to control sample. $\Delta E$ increased with prolonged homogenization time, indicating greater changes in total colour differences after the applied treatments. Longer treatment exhibited a significant impact $(\mathrm{p}<0.05)$ on $\Delta E$ in plain goat's milk sample and the sample enriched with rosemary. These results are in accordance with the observed lightness values, confirming that the approach to formulating new products by enrichment with liquid plant extracts and subsequent ultrasound treatment affects the colour of the product, and has to be evaluated by sensory analysis to establish the consumer preferences towards these products.

The use of high intensity ultrasound is necessary to produce cavitation effect on treated milk samples. By implosion of cavitation gas bubbles, high intensity shock waves 
are produced, which directly decreases the fat globule size. By reducing the fat globule size, globules are not able to get on the top of milk after storage and during consumption, thereby allowing better stability of treated samples (25). In this study, the median diameter, $d(0.5)$, of unhomogenized goat's milk samples ranged from 3.01 to $3.31 \mu \mathrm{m}$, where the addition of plant extracts exhibited an insignificant effect $(\mathrm{p}>0.05)$ on the $d(0.5)$ of fat globule size. In all samples, the application of ultrasound resulted in decreased median diameter, regardless of its duration. The lowest $d(0.5)$ was achieved after $10 \mathrm{~min}$ of ultrasound homogenization, where $d(0.5)$ ranged from 0.72 to $1.15 \mu \mathrm{m}$, while after 5 min of treatment $d(0.5)$ varied between 1.94 and $2.38 \mu \mathrm{m}$ (Table 1). According to the obtained results, significant difference $(\mathrm{p}<0.05)$ between $d(0.5)$ values after treatments for 5 and $10 \mathrm{~min}$ (with the exception of rosemary- -enriched sample) and between all unhomogenized samples and samples treated for $10 \mathrm{~min}$ was observed, indicating duration of ultrasound homogenization as a significant parameter affecting the fat globule size, and therefore the stability of evaluated samples. Karlović et al. (26) evaluated the impact of different treatment times (3, 6 and $9 \mathrm{~min}$ ) on particle diameters of goat's milk under the same ultrasound conditions as conducted in this study. They revealed that the duration of $6 \mathrm{~min}$ had a major impact on surface area diameter, resulting in the highest decrease of fat globule size. Since it is reported that the emulsion stability is achieved when fat globule size is in range of $1-3 \mu \mathrm{m}(27)$, it can be stated that the applied ultrasound treatments in the present study, regardless of their duration, enabled the achievement of stability by homogenization, and contributed to the improvement of the physicochemical characteristics of goat's milkbased beverages.

\section{Bioactive composition of plant extracts and enriched goat's milk-based beverages}

In the present paper the development of novel goat's milk beverages was achieved by enrichment with medicinal plant extracts, primarily to enhance the bioactive composition of goat's milk, but also to improve its sensory properties and obtain a more attractive food product, acceptable to a wider consumer population. For this purpose, traditional medicinal plants from the Lamiaceae family (lemon balm, mint, lavender, rosemary and sage) were selected based on their previously determined high bioactive content and favoured aroma properties. Their potent bioactivity, in terms of polyphenolics, and relatively low toxicity have emphasized them as useful ingredients in complementary alternative medicine and as natural supplements (28). Thus, plant extracts used for the enrichment of goat's milk were initially screened for their fibre content, polyphenolic profile and antioxidant capacity, and the results are presented in Table 2.

The fibre content in the evaluated plants was examined in terms of soluble polysaccharides and cellulose. The highest content of soluble polysaccharides was determined in mint (9.3\%), followed by lemon balm (7.4\%), rosemary (6.4\%), lavender (5.2\%) and sage (4.4\%), where the last two differed significantly $(\mathrm{p}<0.05)$ in comparison with mint sample. Cellulose content was determined in a higher extent than soluble polysaccharides in all evaluated plants, with the highest content observed in rosemary $(24.7 \%)$, which differed significantly $(\mathrm{p}<0.05)$ from lemon balm, lavender and mint samples.

In order to support the beneficial polyphenolic profile, total and different subclasses of polyphenols in Lamiaceae plants were examined; more specifically flavonoids, hydroxycinnamic acids, proanthocyanidins, total tannins and flavan-3-ols (Table 2). Total polyphenolic (TP) content differed significantly $(\mathrm{p}<0.05)$ among all plant extracts. Mint extract had the highest TP content, expressed as GAE (4745.4 mg/L), followed by in the descending order: lemon balm $>$ rosemary $>$ lavender $>$ sage. Similar ranking was reported in a study of Muchuweti et al. (29), where mint also had higher polyphenolic content than rosemary and sage. When compared to other studies, certain inconsistencies in the TP content among specific plants were observed; how-

Table 2. Phytochemical profile of evaluated plant extracts

\begin{tabular}{|c|c|c|c|c|c|}
\hline & Lemon balm & Mint & Lavender & Rosemary & Sage \\
\hline \multicolumn{6}{|l|}{$w($ fibre $) / \%$} \\
\hline Soluble polysaccharides & $7.4 \pm 0.2$ & $9.3 \pm 1.1$ & $5.2 \pm 0.1$ & $6.4 \pm 0.2$ & $4.4 \pm 0.3$ \\
\hline Cellulose & $15.1 \pm 0.8$ & $13.8 \pm 0.2$ & $16.8 \pm 0.9$ & $24.7 \pm 0.2$ & $20.5 \pm 0.2$ \\
\hline \multicolumn{6}{|l|}{$\gamma($ polyphenolics $) /(\mathrm{mg} / \mathrm{L})$} \\
\hline $\mathrm{TP}$ as GAE & $4486.4 \pm 59.1$ & $4745.5 \pm 36.4$ & $3186.4 \pm 50.0$ & $3640.9 \pm 22.7$ & $2913.6 \pm 31.8$ \\
\hline TF as GAE & $2690.9 \pm 63.6$ & $2581.8 \pm 45.4$ & $1990.9 \pm 45.4$ & $2240.9 \pm 22.7$ & $1781.8 \pm 36.4$ \\
\hline $\mathrm{HC}$ as $\mathrm{CAE}$ & $766.4 \pm 3.6$ & $835.8 \pm 10.9$ & $423.4 \pm 3.5$ & $594.9 \pm 18.2$ & $445.3 \pm 7.3$ \\
\hline $\mathrm{PAC}$ as $\mathrm{CyE}$ & $7.6 \pm 0.2$ & $14.2 \pm 0.5$ & $10.9 \pm 0.0$ & $7.0 \pm 0.5$ & $8.7 \pm 0.9$ \\
\hline TT as TAE & $583.1 \pm 15.5$ & $280.0 \pm 19.1$ & $685.8 \pm 79.4$ & $437.8 \pm 17.4$ & $514.3 \pm 18.4$ \\
\hline Flavan-3-ols as CE & $49.4 \pm 2.9$ & $18.9 \pm 4.4$ & n.d. & $0.17 \pm 0.01$ & $14.5 \pm 0.0$ \\
\hline $\begin{array}{l}\text { Antioxidant capacity/(mmol/L) } \\
\text { ABTS as TE }\end{array}$ & $20.9 \pm 2.2$ & $22.3 \pm 0.1$ & $14.9 \pm 0.2$ & $14.8 \pm 0.5$ & $11.2 \pm 0.4$ \\
\hline DPPH as TE & $28.44 \pm 0.05$ & $28.2 \pm 0.2$ & $26.66 \pm 0.07$ & $27.7 \pm 0.2$ & $16.2 \pm 0.1$ \\
\hline
\end{tabular}

Values are expressed as mean \pm standard deviation $(N=3) . \mathrm{TP}=$ total polyphenols, $\mathrm{TF}=$ total flavonoids, HC=hydroxycinnamic acid, $\mathrm{PAC}=$ proanthocyanins, $\mathrm{TT}=$ total tannins, $\mathrm{GAE}=$ gallic acid equivalents, $\mathrm{CAE}=$ caffeic acid equivalents, $\mathrm{CyE}=$ cyanidin chloride equivalents, $\mathrm{TAE}=$ tannic acid equivalents, $\mathrm{CE}=$ catechin equivalents, $\mathrm{TE}=$ Trolox equivalents, $\mathrm{n} . \mathrm{d}=$ not detected 
ever, those differences are not surprising since it has been well established that the polyphenolic content varies depending on different plant varieties, environmental conditions, climatic differences, seasonal variations, degree of ripeness, growing practices, geographical regions of growth, harvest handling, processing and storage conditions (30). For instance, Generalić Mekinić et al. (31) reported the highest TP content in sage extract, followed by lemon balm and mint, but they obtained slightly higher values than ours. Total flavonoid (TF) content order was similar to the TP content, with lemon balm and mint extracts characterized with the highest, and sage with the lowest TF content. In all samples, total flavonoids contributed to more than a half of total polyphenolic content (approx. 55-60 \%). Mint extract was again distinguished with the highest content of hydroxycinnamic acids, expressed as CAE $(835.8 \mathrm{mg} / \mathrm{L})$, while the lowest was observed in lavender extract. Proanthocyanidins again prevailed in the mint extract $(14.2 \mathrm{mg} / \mathrm{L}$, expressed as $\mathrm{CyE})$, while a significantly $(p<0.05)$ lower content was obtained in rosemary extract, reaching even $50 \%$ lower content of proanthocyanidins. Tannins, polyphenolic compounds responsible for astringency and bitterness, varied significantly $(\mathrm{p}<0.05)$ among the plant species. The highest content of tannins was determined in lavender extract $(685.8 \mathrm{mg} / \mathrm{L})$. When expressed in percentage of dry mass of plant, tannin content in lavender amounted to $1.4 \%$, which is in accordance with the results obtained in a study of Komes et al. (21). Additionally, opposite to the ranking of other polyphenolic compounds, mint extract was characterized with the lowest tannin content. Lemon balm extract had significantly $(\mathrm{p}<0.05)$ higher content of flavan-3-ols than other plants.

The antioxidant capacity of medicinal plants was evaluated by two in vitro assays (ABTS and DPPH). The obtained results confirmed a similar ranking as for TP content determined in plant species. By applying ABTS assay, mint extract was characterized with the highest antioxidant capacity, expressed as TE $(22.3 \mathrm{mmol} / \mathrm{L})$, which was significantly higher $(p<0.05)$ than of other extracts. By employing DPPH assay, lemon balm was characterized with the most prominent antioxidant capacity, expressed as TE $(28.4 \mathrm{mmol} / \mathrm{L})$, followed by negligibly lower antioxidant capacity of mint extract. Again, by using the DPPH assay, sage extract exhibited the lowest antioxidant capacity.

After a thorough bioactive characterization, the plant extracts were added to goat's milk for preparation of enriched goat's milk beverages and the prepared samples were subjected to ultrasound homogenization in duration of 5 and $10 \mathrm{~min}$. The bioactive profile of prepared innovative beverages was analysed, in terms of their TP and TF contents, and antioxidant capacity. TP and TF contents of enriched goat's milk samples are shown in Fig. 1. As was expected, the polyphenolic content of goat's milk was markedly improved after the addition of plant extracts. The addition of mint extract resulted in the highest TP content (as GAE) of enriched goat's milk beverages, ranging from 638.2 to 755.5 $\mathrm{mg} / \mathrm{L}$ (depending on the homogenization conditions). The addition of lavender and sage extracts contributed at least to the improvement of TP content in the enriched goat's milk beverages (Fig. 1a).

These results follow the pattern of TP content determined in aqueous plant extracts, where mint extract was

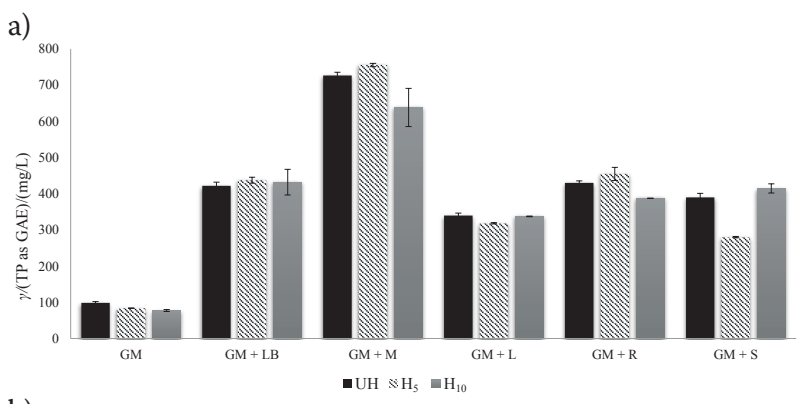

b)

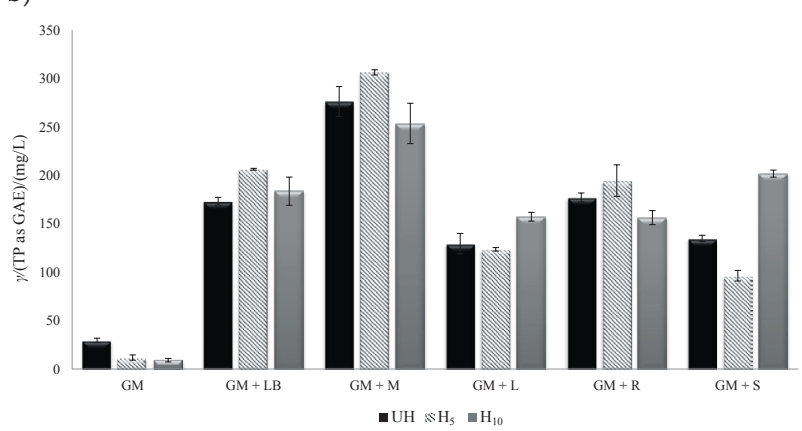

Fig. 1. Total polyphenol (TP; a) and total flavonoid (TF; b) contents of plain and goat's milk enriched with plant extracts prior to (unhomogenized) and after ultrasound homogenization. Values are expressed as mean \pm standard deviation $(N=3)$. GM=goat's milk, $\mathrm{GM}+\mathrm{LB}=\mathrm{GM}$ enriched with lemon balm extract, $\mathrm{GM}+\mathrm{M}=\mathrm{GM}$ enriched with mint extract, $\mathrm{GM}+\mathrm{L}=\mathrm{GM}$ enriched with lavender extract, $\mathrm{GM}+\mathrm{R}=\mathrm{GM}$ enriched with rosemary extract, $\mathrm{GM}+\mathrm{S}=\mathrm{GM}$ enriched with sage extract, $\mathrm{UH}=$ unhomogenized samples, $\mathrm{H}_{5}$ and $\mathrm{H}_{10}=$ samples homogenized for 5 and $10 \mathrm{~min}$, respectively

also characterized with the highest, while sage and lavender with the lowest TP content. According to the obtained values, samples enriched with mint extract had significantly higher $(\mathrm{p}<0.05)$ TP content than other enriched samples, implying that the adequate choice of plant species could play an important role when developing new food products with improved bioactive profile. Generally, ultrasound treatments resulted in a significant impact on TP content of evaluated enriched goat's milk beverages. However, due to the fluctuations in TP content after applied homogenization treatments, it was hard to determine a specific uniform trend in TP pattern of enriched samples, regardless of their duration. Insignificant effect of ultrasound homogenization $(p>0.05)$ on TP was observed only in the samples enriched with lavender (untreated sample and sample treated for $10 \mathrm{~min}$ ) and lemon balm (samples treated for 5 and $10 \mathrm{~min}$ ) extracts.

The addition of plant extracts to goat's milk had an equal effect on the TF ranking (as shown for TP) (Fig. 1b). Duration of ultrasound treatments ( 5 and $10 \mathrm{~min}$ ) had a significant influence $(p<0.05)$ on TF content of enriched goat's milk samples, with the exception of lavender extract, where shorter treatment time (5 min) had insignificant influence $(p>0.05)$ on the TF of the evaluated sample. Generally, up to 7-fold higher TP and TF contents were achieved by enrichment of goat's milk with plant extracts, when compared to plain goat's milk, which supports the fact that the bioactive profile of goat's milk beverages was markedly enhanced by the addition of aqueous plant extracts. 
After screening of polyphenols, the antioxidant capacity of enriched goat's milk samples was studied using ABTS and DPPH radical scavenging assays. Among all evaluated samples, ABTS revealed higher antioxidant capacity than DPPH scavenging assay, with negligible exceptions (Fig. 2). Such results could be attributed to the differences among reaction principles, since it is known that ABTS radical reacts with both hydrophilic and lipophilic antioxidants, while the DPPH radical reacts only with lipophilic antioxidants. Therefore, in this study, lipophilic antioxidants naturally present in milk possibly contribute to the higher antioxidant capacity of enriched samples obtained by the ABTS assay. Also, negligible antioxidant capacity determined by the ABTS assay was also observed in plain goat's milk, which could be attributed to the presence of lipophilic antioxidants in milk, since by applying DPPH assay, the antioxidant capacity of plain goat's milk was not detected. This fact also confirms that the influence of milk antioxidants on total antioxidant capacity of enriched milk samples is insignificant in comparison with the contribution of antioxidants derived from plant extracts, indicating that the antioxidant capacity of enriched goat's milk is the consequence solely of the plant extracts. Upon the addition of plant extracts, the antioxidant capacity of goat's milk beverages increased up to $3 \mathrm{mmol}$ TE per L, which is comparable to the antioxidant capacity of green tea (32), coffee (33) or chocolate (34), as some of the most well known antioxidants. The antioxidant capacity obtained by both scavenging assays again revealed the antioxidant superiority of mint-enriched goat's milk beverages.

Among homogenized samples, shorter treatment time (5 min) resulted in decreased antioxidant capacity (with the exception of DPPH sample enriched with rosemary), while longer treatment duration (10 min) provided increased antioxidant capacity, in some cases even higher than in unhomogenized sample. The possible increase in the antioxidant capacity after prolonged treatment may be attributed to the disruption of protein-polyphenol complexes that may have been formed within the enriched goat's milk beverages. Namely, polyphenols are highly reactive molecules that can get into interaction with different macromolecules, like proteins, carbohydrates and enzymes, and in the end lead to the formation of different polyphenol-macromolecule complexes (35). They also possess high affinity for binding protein molecules rich in proline, as the casein in milk (36). Therefore, the prolongation of ultrasound treatment may have contributed to the degradation of these complexes and liberation of polyphenolic antioxidants, which resulted in their higher reactivity and higher antioxidant capacity. However, there was no significant influence ( $p>0.05)$ of applied homogenization treatment duration on the antioxidant capacity of evaluated enriched samples determined by both assays. Although the homogenization treatments exhibited a variable effect on the antioxidant capacity of the obtained beverages, the significantly improved antioxidant capacity upon the addition of plant extracts has justified the use of these substrates for enrichment purposes.

Results of the HPLC analysis of plant extracts and goat's milk enriched with plant extracts are summarized in Table 3. All samples were characterized with higher phenolic acid contents than detected flavone derivatives. Significant differences among specific plant extracts $(\mathrm{p}<0.05)$ in each polyphe-

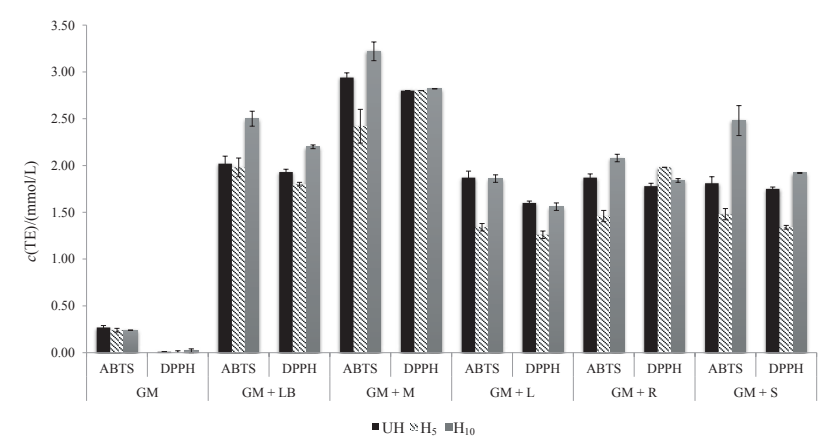

Fig. 2. Antioxidant capacity (expressed as Trolox equivalent, TE) of plain and goat's milk enriched with plant extracts prior to (unhomogenized) and after ultrasound homogenization, determined by ABTS and DPPH radical scavenging assays. Values are expressed as mean \pm standard deviation $(N=3)$. GM=goat's milk, GM+LB=GM enriched with lemon balm extract, $G M+M=G M$ enriched with mint extract, $\mathrm{GM}+\mathrm{L}=\mathrm{GM}$ enriched with lavender extract, $\mathrm{GM}+\mathrm{R}=\mathrm{GM}$ enriched with rosemary extract, $\mathrm{GM}+\mathrm{S}=\mathrm{GM}$ enriched with sage extract, $\mathrm{UH}=$ unhomogenized samples, $\mathrm{H}_{5}$ and $\mathrm{H}_{10}=$ samples homogenized for 5 and 10 min, respectively

nolic compound were observed, confirming the diverse, but beneficial polyphenolic composition among plant species.

Among the identified polyphenolic compounds, rosmarinic acid (RA) was the most abundant in all samples. Rosmarinic acid (an ester of caffeic acid and 3,4-dihydroxyphenyllactic acid) is one of the major polyphenolics from the group of hydroxycinnamic acids, and it can be considered as a representative marker of the Lamiaceae family (37). Rosemary extract was the richest source of RA $(1898.4 \mathrm{mg} / \mathrm{L})$, followed by the lemon balm $>$ mint $>$ sage $>$ lavender extracts. Amaral et al. (38) obtained $38.5 \mathrm{mg}$ of RA per g of ethanolic extract, which is consistent with the results obtained in this study (38 mg/g). However, Kontogianni et al. (28) quantified lower contents of RA in rosemary extract. As mentioned before, various external and environmental factors influencing plant growth could contribute to the fluctuations in polyphenolic content and composition. Also, the same extraction technique, its conditions (time and temperature, solvent) and different identification and quantification assays could lead to scattered results in polyphenolic content among studies.

The addition of plant extracts to goat's milk resulted in a variable final content of individual polyphenolic compounds in the obtained beverages. Although the content of plant extracts added to goat's milk for the formulation of beverages was $10 \%$ of the final beverage volume, the enriched goat's milk beverages contained higher content of specific polyphenols than the theoretical one. In the case of RA, up to $30 \%$ of the initial RA content (plain plant extracts) was detected in the enriched goat's milk beverages. These findings indicate that goat's milk is an appropriate food substrate for the implementation of aqueous plant extracts allowing the preservation of the bioactive components. With regard to ultrasound homogenization, treatments had a different impact on RA content, in dependence on the treatment duration. For example, in goat's milk enriched with rosemary extract, shorter ultrasound treatment exhibited an increase $(\mathrm{p}<0.05)$ in RA, while in the milk with lavender extract, the 10-minute 
Table 3. The content of individual polyphenolic compounds in plant extracts and goat's milk enriched with plant extracts prior to (unhomogenized) and after ultrasound homogenization

\begin{tabular}{|c|c|c|c|c|c|c|c|c|}
\hline \multirow{3}{*}{ Sample } & \multicolumn{8}{|c|}{$\gamma /(\mathrm{mg} / \mathrm{L})$} \\
\hline & \multicolumn{5}{|c|}{ Phenolic acids } & \multicolumn{3}{|c|}{ Flavones } \\
\hline & RA & ChlA & $\mathrm{CA}$ & $p$-CoumA & $\Sigma \mathrm{HcAD}$ & $\sum$ LutD & $\sum$ RutD & $\sum$ ApiD \\
\hline \multicolumn{9}{|c|}{$\mathrm{GM}+\mathrm{LB}$} \\
\hline LB & $1618.3 \pm 35.6$ & $33.3 \pm 1.1$ & $12.3 \pm 1.7$ & n.d. & $997.1 \pm 88.0$ & $26.5 \pm 1.9$ & $29.0 \pm 2.2$ & n.d. \\
\hline $\mathrm{UH}$ & $293.2 \pm 16.7$ & $13.7 \pm 1.6$ & $2.2 \pm 0.3$ & n.d. & $71.0 \pm 5.5$ & n.d. & n.d. & n.d. \\
\hline $\mathrm{H}_{5}$ & $254.6 \pm 24.4$ & $4.0 \pm 0.1$ & $2.2 \pm 0.1$ & n.d. & $49.2 \pm 2.2$ & n.d. & n.d. & n.d. \\
\hline $\mathrm{H}_{10}$ & $310.4 \pm 7.2$ & $4.9 \pm 0.4$ & $2.5 \pm 0.4$ & n.d. & $82.6 \pm 3.8$ & n.d. & n.d. & n.d. \\
\hline \multicolumn{9}{|c|}{$\mathrm{GM}+\mathrm{M}$} \\
\hline M & $1443.1 \pm 72.0$ & $19.7 \pm 0.9$ & n.d. & $0.30 \pm 0.01$ & $300.2 \pm 11.6$ & $263.4 \pm 13.6$ & $1053.4 \pm 63.6$ & n.d. \\
\hline $\mathrm{UH}$ & $251.5 \pm 24.7$ & $3.4 \pm 0.4$ & n.d. & n.d. & $57.8 \pm 2.8$ & $124.1 \pm 11.6$ & n.d. & n.d. \\
\hline $\mathrm{H}_{5}$ & $272.2 \pm 20.6$ & $3.2 \pm 0.4$ & n.d. & n.d. & $45.8 \pm 2.4$ & $124.4 \pm 11.0$ & n.d. & n.d. \\
\hline $\mathrm{H}_{10}$ & $256.6 \pm 28.7$ & $3.7 \pm 0.1$ & n.d. & n.d. & $30.0 \pm 2.0$ & $124.3 \pm 5.3$ & n.d. & n.d. \\
\hline \multicolumn{9}{|c|}{$\mathrm{GM}+\mathrm{L}$} \\
\hline $\mathrm{L}$ & $349.1 \pm 21.1$ & $37.6 \pm 3.5$ & n.d. & n.d. & $694.0 \pm 44.0$ & $57.9 \pm 1.8$ & n.d. & n.d. \\
\hline $\mathrm{UH}$ & $52.8 \pm 8.1$ & $6.3 \pm 0.6$ & n.d. & n.d. & $219.7 \pm 24.9$ & $11.2 \pm 1.6$ & n.d. & n.d. \\
\hline $\mathrm{H}_{5}$ & $64.1 \pm 6.0$ & $4.00 \pm 0.3$ & n.d. & n.d. & $87.1 \pm 3.0$ & $11.0 \pm 1.6$ & n.d. & n.d. \\
\hline $\mathrm{H}_{10}$ & $48.6 \pm 1.3$ & $7.3 \pm 0.5$ & n.d. & n.d. & $197.6 \pm 9.6$ & $10.4 \pm 1.6$ & n.d. & n.d. \\
\hline \multicolumn{9}{|c|}{$\mathrm{GM}+\mathrm{R}$} \\
\hline $\mathrm{R}$ & $1898.4 \pm 83.2$ & $8.6 \pm 1.1$ & $6.3 \pm 0.6$ & n.d. & $141.8 \pm 11.4$ & $44.5 \pm 2.6$ & n.d. & n.d. \\
\hline $\mathrm{UH}$ & $291.6 \pm 26.5$ & n.d. & $3.0 \pm 0.2$ & n.d. & $15.7 \pm 2.9$ & $4.18 \pm 0.06$ & n.d. & n.d. \\
\hline $\mathrm{H}_{5}$ & $316.2 \pm 28.2$ & n.d. & $2.4 \pm 0.3$ & n.d. & $8.9 \pm 0.1$ & $7.5 \pm 0.4$ & n.d. & n.d. \\
\hline $\mathrm{H}_{10}$ & $286.5 \pm 27.0$ & n.d. & $2.8 \pm 0.3$ & n.d. & $22.2 \pm 2.2$ & $9.4 \pm 1.0$ & n.d. & n.d. \\
\hline \multicolumn{9}{|c|}{$\mathrm{GM}+\mathrm{S}$} \\
\hline$S$ & $355.7 \pm 16.2$ & $11.5 \pm 1.6$ & $16.3 \pm 1.4$ & n.d. & $77.6 \pm 1.9$ & $190.6 \pm 18.6$ & n.d. & $4.10 \pm 0.02$ \\
\hline $\mathrm{UH}$ & $132.6 \pm 11.6$ & $3.7 \pm 0.3$ & $1.7 \pm 0.2$ & n.d. & $39.6 \pm 4.3$ & $40.3 \pm 2.0$ & n.d. & n.d. \\
\hline $\mathrm{H}_{5}$ & $99.3 \pm 5.0$ & $2.6 \pm 0.3$ & $1.4 \pm 0.1$ & n.d. & $33.4 \pm 3.1$ & $29.5 \pm 2.2$ & n.d. & n.d. \\
\hline $\mathrm{H}_{10}$ & $133.1 \pm 12.0$ & $4.6 \pm 0.3$ & $2.2 \pm 0.3$ & n.d. & $42.5 \pm 4.3$ & $39.1 \pm 3.3$ & n.d. & n.d. \\
\hline
\end{tabular}

Values are expressed as mean \pm standard deviation $(N=3)$. $\mathrm{GM}=$ goat's milk, $\mathrm{GM}+\mathrm{LB}=\mathrm{GM}$ enriched with lemon balm extract, $\mathrm{GM}+\mathrm{M}=\mathrm{GM}$ enriched with mint extract, $\mathrm{GM}+\mathrm{L}=\mathrm{GM}$ enriched with lavender extract, $\mathrm{GM}+\mathrm{R}=\mathrm{GM}$ enriched with rosemary extract, $\mathrm{GM}+\mathrm{S}=\mathrm{GM}$ enriched with sage extract, $\mathrm{UH}=$ unhomogenized samples, $\mathrm{H}_{5}=$ samples homogenized for $5 \mathrm{~min}, \mathrm{H}_{10}=$ samples homogenized for 10 min, $\mathrm{RA}=$ rosmarinic acid, $\mathrm{ChlA}=$ chlorogenic acid, $\mathrm{CA}=$ caffeic acid, $p$-CoumA=p-coumaric acid, $\Sigma \mathrm{HcAD}, \Sigma \mathrm{LutD}, \Sigma$ RutD and $\Sigma \mathrm{ApiD}=$ sum of hydroxycinnamic acids (expressed as rosmarinic acid), luteolin, rutin and apigenin derivatives, respectively, n.d.=not detected

treatment caused an insignificant $(\mathrm{p}>0.05)$ decrease of RA content. Therefore, due to the reported discrepancies among the results, exact influence of ultrasound homogenization on RA content was hard to establish.

Chlorogenic acid (ChlA) was detected in the highest concentration in lavender extract $(37.6 \mathrm{mg} / \mathrm{L})$, and the lowest was determined in rosemary extract $(8.6 \mathrm{mg} / \mathrm{L})$. Vallverdú-Queralt et al. (39) confirmed the presence of ChlA in rosemary; however, in much lower concentration. Since ChlA was detected in rosemary extract only in a minor concentration, it was not detected in enriched goat's milk samples. The addition of $10 \%$ of plant extracts to goat's milk for the formulation of enriched beverages also enabled a higher ChlA content of the obtained beverages (than the theoretical content of plain plant extracts).
Among hydroxycinnamic acids, caffeic acid (CA) was also detected, with sage extract as the representative source of this compound $(16.3 \mathrm{mg} / \mathrm{L})$, while it was not detected in mint and lavender samples, again confirming significant differences among the plant compositions. The homogenization treatments had an insignificant effect $(p>0.05)$ on the contents of both chlorogenic and caffeic acids in the enriched goat's milk samples. Due to the diversity of hydroxycinnamic acids, as the group of compounds representative of the evaluated plant extracts, these compounds were also evaluated as the hydroxycinnamic acid derivatives, expressed as their sum ( $\sum$ HcAD). HcAD again exhibited marked differences between the plant species, and the $\sum$ HcAD was the most abundant in lemon balm extract (997.1 mg/L). Consequently, markedly different concentration of HcAD in the formulated goat's milk beverages de- 
pendening on the added plant extract was measured. No specific trend in the total $\Sigma$ HcAD content was observed with regard to ultrasound duration. These inconsistencies may be the result of the variability and diversity of HcAD, which may also have variable properties and reactivity in the implemented matrix, in this case goat's milk. Apart from the phenolic acids, plant extracts in different concentrations also represent a source of flavone derivatives (luteolin, rutin and apigenin). Mint extract had the highest concentration of luteolin derivatives $\left(\sum \mathrm{LutD}=263.4 \mathrm{mg} / \mathrm{L}\right)$, followed by sage extract, while other samples contained considerably lower concentrations, ranging from 26.5 to $58.0 \mathrm{mg} / \mathrm{L}$. Rutin derivatives were only detected in lemon balm and mint extracts, where mint represented the main source of these compounds ( $\sum$ RutD $=1053.4 \mathrm{mg} / \mathrm{L}$ ), even 36 times higher than in lemon balm. Finally, sage extract was the only source of apigenin derivatives $\left(\sum \mathrm{ApiD}=4.10 \mathrm{mg} / \mathrm{L}\right)$. The presence of apigenin in sage extract was also confirmed by Kontogianni et al. (28). Upon the addition of plant extracts to goat's milk, only LutD were detected in the formulated beverages (with the exception of lemon balm-enriched goat's milk), while RutD and ApiD were not detected at all. Consistent with the highest TPC and antioxidant capacity, the addition of mint enabled the highest LutD content of the enriched beverages, even higher than the total HcAD content. The established variability and diversity of the detected polyphenolic compounds is beneficial for the enriched goat's milkbased beverages, since it is well known that the combination of diverse polyphenolic antioxidants deriving from a natural substrate may exert a potent, synergistic effect with beneficial health effects and activities.

\section{Sensory properties of plant extracts and formulated enriched goat's milk beverages}

Goat's milk flavour originates from the lipid fractions, characterised by a strong scent and specific flavour. Important contributors to the distinctive goat's milk taste are free fatty acids (caprylic, capric and caproic), where 4-methyloctanoic acid and 4-ethyloctanoic acid have been found to be principally responsible for the goat's milk flavour, since they are perceived even at very low concentrations and present at levels higher than their perception threshold (40). These fatty acids remain bound in glycerides during milk processing and thus contribute to the consumer perception of goat's milk, which is most often not preferred among consumers. Therefore, to make goat's milk closer to consumers and develop stable, innovative, highly valuable and sensorially desirable product, plant extracts were added to the goat's milk with the aim of improving its sensory characteristics.

Among plant extracts, as can be seen in Fig. 3a, certain differences in the sensory preference among the evaluated extracts were observed. There was no significant difference $(p>0.05)$ in the flavour among evaluated plant extracts. Lavender extract, characterised by the highest bitterness, was the least preferred by the panellists. Also, in terms of bitterness, lavender extract was significantly different $(\mathrm{p}<0.05)$ only from mint extract. The highest astringency was evaluated in rosemary extract, which was significantly higher $(\mathrm{p}<0.05)$ than values observed for lemon balm, mint and sage. Lemon balm scored the highest values of sweetness, and the lowest of astringency. Sweetness of lemon balm was significantly different $(\mathrm{p}<0.05)$ from other plant extracts (mint, lavender, rosemary and sage), while its astringency was significantly different $(\mathrm{p}<0.05)$ only from that of rosemary. The highest overall acceptability was recorded for mint extract, which can be related to its least pronounced bitterness and astringency. Overall acceptability of mint was not significantly different $(p>0.05)$ from the one determined for rosemary, which among panellists was the second rated in terms of overall acceptability.

According to the obtained results (Fig. 3b), sensory profile of enriched goat's milk beverages was significantly improved. As expected, plain goat's milk was not preferred among panellists and resulted in low overall acceptability, which was significantly enhanced after the addition of plant extracts. Flavour, as one of the most important attributes, scored very high among other evaluated sensory properties, especially in milk samples enriched with lavender and mint extracts. This may be the consequence of the flavour familiarity which scored highest for these two extracts. Flavour of milk samples enriched with lavender and mint was significantly different $(\mathrm{p}<0.05)$ from flavour of other enriched goat's milk samples. However, due to the highest bitterness and astringency of lavender extract, goat's milk containing lavender was also characterized by the highest intensity of these properties and thus conse-

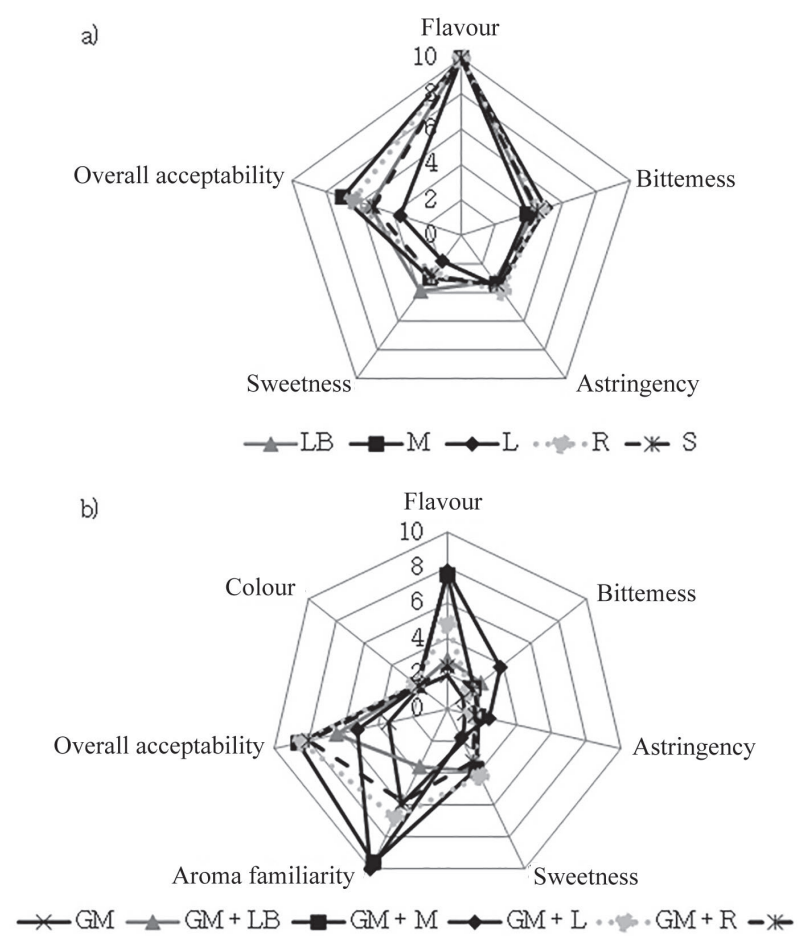

Fig. 3. Mean scores of the evaluated sensory attributes of: a) plant extracts, b) plain and goat's milk enriched with plant extracts. Scores 0 -10 represent the average point number $(N=15)$ of scores $(1-5)$ for each attribute multiplied with an importance factor (IF) determined for each attribute (IF $=2$ for flavour, overall acceptability and aroma familiarity, IF $=1.5$ for sweetness, $\mathrm{IF}=1$ for bitterness and astringency and $\mathrm{IF}=0.5$ for colour). $\mathrm{LB}=$ lemon balm, $\mathrm{M}=$ mint, $\mathrm{L}=$ lavender, $\mathrm{R}=$ rosemary, $\mathrm{S}=$ sage, $\mathrm{GM}=$ plain goat's milk, $\mathrm{GM}+\mathrm{LB}=\mathrm{GM}$ enriched with lemon balm extract, $\mathrm{GM}+\mathrm{M}=\mathrm{GM}$ enriched with mint extract, $\mathrm{GM}+\mathrm{L}=\mathrm{GM}$ enriched with lavender extract, $G M+R=G M$ enriched with rosemary extract, $\mathrm{GM}+\mathrm{S}=\mathrm{GM}$ enriched with sage extract 
quently low overall acceptability. Bitterness and overall acceptability of milk containing lavender were significantly different $(p<0.05)$ compared to other enriched milk samples. In contrast, the addition of mint and rosemary extracts, which were characterized by a high overall acceptability of plain extracts, also provided the best, i.e. the highest overall acceptability of enriched goat's milk beverages. This can be attributed also to the pronounced sweetness of rosemary-enriched goat's milk and can imply the potential masking effect of the specific goat's milk flavour. Sweetness of milk enriched with rosemary was significantly different $(\mathrm{p}<0.05)$ in comparison with the sweetness of lavenderand sage-enriched milk samples. Generally, it was observed that the addition of all plant extracts enhanced the sweetness perception of goat's milk in comparison with plain goat's milk, while the addition of sage extract contributed the least to the flavour improvement (with no significant difference ( $\mathrm{p}>0.05$ ) compared to plain goat's milk). The addition of $10 \%$ of extracts to goat's milk showed insignificant $(p>0.05)$ influence on colour, since the colour of enriched milk samples changed slightly. However, the most prominent colour change was observed after the addition of rosemary extract. Based on the obtained results, it can be deduced that the final ranking of plant extracts according to the sensory properties of the obtained product is as follows: mint $>$ rosemary $>$ sage $>$ lemon balm $>$ lavender. This indicates that consumers would prefer the addition of mint and rosemary extracts to products, mostly due to the aroma familiarity and positive taste attributes. The use of sage and lemon balm is not as preferred due to their mild aroma, while the addition of lavender extract does not provide a sufficient improvement of the sensory characteristics of goat's milk.

\section{Conclusions}

In this study, goat's milk beverages enriched with medicinal plant extracts, homogenized and stabilized by applying nonthermal high intensity ultrasound treatments were produced. The enriched beverages were characterized with significantly improved bioactive compound content and profile, derived from polyphenolic antioxidants of medicinal plants. The addition of plant extracts, besides providing specific polyphenolic compounds that are not normally present in goat's milk, also enabled to achieve products characterized by antioxidant capacity comparable to that of green tea, coffee or chocolate. Employing mint extract enabled the highest increase in the bioactive compound content. Ultrasound homogenization significantly affected only the physicochemical properties of enriched goat's milk beverages, mainly fat globule size reduction, colour difference and decrease in the content of proteins, lactose or $\mathrm{pH}$, while it had no specific effect on the bioactive compound content. The main purpose of masking and reducing the negative sensory properties of goat's milk was achieved by enrichment with plant extracts, which was in the highest measure achieved by the addition of mint and rosemary extracts, as evidenced by the highest overall acceptability of the formulated beverages. Taking into account numerous health benefits of plain goat's milk and medicinal plants, the enriched goat's milk beverages could gain higher interest among consumers and present an innovative, consumer appealing functional food product.

\section{References}

1. Zheng W, Wang SY. Antioxidant activity and phenolic compounds in selected herbs. J Agric Food Chem. 2001;49:5165-70. https://doi.org/10.1021/jf010697n

2. Brncic M, Herceg Ljubic I, Subaric D, Badanjak M, Rimac Brncic S, Tripalo B, et al. Influence of power ultrasound on textural properties of corn starch gels. In: Fischer P, Pollard M, Windhab EJ, editors. Proceedings of the 5th International Symposium on Food Rheology and Structure; 2009 June 15-18, Zürich, Switzerland: Laboratory of Food Process Engineering, Institute of Food Science and Nutrition, ETH Zürich; 2009. pp. 500-1.

3. O'Donnell CP, Tiwari BK, Bourke P, Cullen PJ. Effect of ultrasonic processing on food enzymes of industrial importance. Trends Food Sci Technol. 2010;21:358-67. https://doi.org/10.1016/j.tifs.2010.04.007

4. Guzey D, McClements DJ. Formation, stability and properties of multilayer emulsion for application in the food industry. Adv Colloid Interface Sci. 2006;128-130:227-48.

https://doi.org/10.1016/j.cis.2006.11.021

5. López-Aliaga I, Alférez MJM, Barrionuevo M, Nestares T, Sanz Sampelayo MR, Campos MS. Study of nutritive utilization of protein and magnesium in rats with resection on the distal small intestine. Beneficial effect of goat milk. J Dairy Sci. 2003;86:2958-66.

https://doi.org/10.3168/jds.S0022-0302(03)73893-4

6. Ribeiro AC, Ribeiro SDA. Specialty products made from goat milk. Small Ruminant Res. 2010;89:225-33.

https://doi.org/10.1016/j.smallrumres.2009.12.048

7. Akahoshi R, Takahashi Y. Yoghurt containing Bifidobacterium and process for producing the same. Patent WO 1996037113 A1. 1996.

8. Pszczola DE. The ABCs of nutraceutical ingredients. Food Technol. 1998;52:30-7.

9. Howard AN, Nigdikar SV, Rajput-Williams J, Williams NR. Food supplements. US patent US 6086910 A. 2000.

10. Halah MF, Mehanna NS. Use of natural plant antioxidant and probiotic in the production of novel yogurt. J Evol Biol Res. 2011;3:12-8.

11. Karaaslan M, Ozden M, Vardin H, Turkoglu H. Phenolic fortification of yogurt using grape and callus extracts. LWT - Food Sci Technol. 2011;44:1065-72. https://doi.org/10.1016/j.lwt.2010.12.009

12. Servili M, Rizzello CG, Taticchi A, Esposto S, Urbani S, Mazzacane F, et al. Functional milk beverage fortified with phenolic compounds extracted from olive vegetation water, and fermented with functional lactic acid bacteria. Int J Food Microbiol. 2011;147:45-52.

https://doi.org/10.1016/j.ijfoodmicro.2011.03.006

13. Aliakbarian B, Casale M, Paini M, Casazza AA, Lanteri S, Perego P. Production of a novel fermented milk fortified with natural antioxidants and its analysis by NIR spectroscopy. LWT - Food Sci Technol. 2015;62:376-83. https://doi.org/10.1016/j.lwt.2014.07.037

14. Tijskens LMM, Schijvens EPHM, Biekman ESA. Modelling the change in colour of broccoli and green beans during blanching. Innov Food Sci Emerg Technol. 2001;2:303-13. https://doi.org/10.1016/S1466-8564(01)00045-5

15. Wei HC, Rollins J, Fabian L, Hayes M, Polevoy G, Bazinet C, Brill JA. Depletion of plasma membrane PtdIns $(4,5) \mathrm{P}_{2}$ reveals essential roles for phosphoinositides in flagellar biogenesis. J Cell Sci. 2008;121:1076-84.

https://doi.org/10.1242/jcs.024927 
16. Thaler H. Determination of cellulose and other cell wall components. In: Schormüller J, editor. Handbook of food chemistry, vol. II., part 2. Analysis of foods. Determination of food constituents. Berlin, Germany: Springer-Verlag; 1967. p. 514 (in German).

17. Lachman J, Hosnedl V, Pivec V, Orsak M. Polyphenols in cereals and their positive and negative role in human and animal nutrition. In: Vaculová K, Ehrenbergerová J, editors. Cereals for human health and preventive nutrition: Proceedings of the conference; 1998 July 7-11; Brno, Czech Republic: Agricultural Research Institute Kroměříz Ltd.; 1998. pp. 118-25.

18. Matkowski A, Tasarz P, Szypuła E. Antioxidant activity of herb extracts from five medicinal plants from Lamiaceae, subfamily Lamioideae. J Med Plant Res. 2008;2:321-30.

19. Porter LJ, Hrstich LN, Chan BG. The conversion of procyanidins and prodelphinidins to cyanidin and delphinidin. Phytochemistry. 1985;25:223-30. https://doi.org/10.1016/S0031-9422(00)94533-3

20. Rusak G, Kuštrak D, Maleš Ž, Pleše N. The determination of the content of the polyphenols in the areal parts of the species Centaurea rupestris L. and C. fritschii Hayek (Asteraceae). Acta Pharmaceut. 1993;43:121-5.

21. Komes D, Belščak-Cvitanović A, Horžić D, Rusak G, Likić S, Berendika M. Phenolic composition and antioxidant properties of some traditionally used medicinal plants affected by the extraction time and hydrolysis. Phytochem Anal. 2011;22:172-80. https://doi.org/10.1002/pca.1264

22. Re R, Pellegrini N, Proteggente A, Pannala A, Yang M, Rice-Evans C. Antioxidant activity applying an improved ABTS radical cation decolorization assay. Free Radic Biol Med. 1999;26:12317. https://doi.org/10.1016/S0891-5849(98)00315-3

23. Brand-Williams W, Cuvelier ME, Berset C. Use of free radical method to evaluate antioxidant activity. LWT - Food Sci Technol. 1995;28:25-30. https://doi.org/10.1016/S0023-6438(95)80008-5

24. STATISTICA, v. 7.0, StatSoft, Inc, Tulsa, OK, USA; 2008. Available from: http://www.statsoft.com.

25. Luque de Castro MD, Capote FP, editors. Analytical applications of ultrasound. Oxford, UK: Elsevier; 2007.

26. Karlović S, Bosiljkov T, Brnčić M, Semenski D, Dujmić F, Tripalo $\mathrm{B}$, Ježek D. Reducing fat globules particle-size in goat milk: Ultrasound and high hydrostatic pressures approach. Chem Biochem Eng Q. 2014;28:499-507.

https://doi.org/10.15255/CABEQ.2014.19400

27. Bosiljkov T, Brnčić M, Tripalo B, Karlović S, Ukrainczyk M, Ježek D, Rimac Brnčić S. Impact of ultrasound-enhanced homogenization on physical properties of soybean milk. In: Pierucci S, editor. Proceedings of the 9th International Conference on Chemical and Process Engineering; 2009 May 10-13; Rome, Italy: AIDIC; 2009. pp. 1029-34.

28. Kontogianni VG, Tomic G, Nikolic I, Nerantzaki AA, Sayyad N, Stosic-Grujicic S, et al. Phytochemical profile of Rosmarinus officinalis and Salvia officinalis extracts and correlation to their antioxidant and antiproliferative activity. Food Chem. 2013;136:120-9.

https://doi.org/10.1016/j.foodchem.2012.07.091
29. Muchuweti M, Kativu E, Mupure $\mathrm{CH}$, Chidewe C, Ndhlala AR, Benhura MAN. Phenolic composition and antioxidant properties of some spices. Am J Food Technol. 2007;2:414-20. https://doi.org/10.3929/ajft.2007.414.420

30. Yesil-Celiktas O, Girgin G, Orhan H, Wichers HJ, Bedir E, Vardar-Sukan F. Screening of free radical scavenging capacity and antioxidant activities of Rosmarinus officinalis extracts with focus on location and harvesting times. Eur Food Res Technol. 2007;224:443-51. https://doi.org/10.1007/s00217-006-0306-0

31. Generalić Mekinić I, Skroza D, Ljubenkov I, Šimat V, Smole Možina S, Katalinić V. In vitro antioxidant and antibacterial activity of Lamiaceae phenolic extracts: A correlation study. Food Technol Biotechnol. 2014;52:119-27.

32. Komes D, Horžić D, Belščak A, Kovačević Ganić K, Vulić I. Green tea preparation and its influence on the content of bioactive compounds. Food Res Int. 2010;43:167-76. https://doi.org/10.1016/j.foodres.2009.09.022

33. Hečimović I, Belščak-Cvitanović A, Horžić D, Komes D. Comparative study of polyphenols and caffeine in different coffee varieties affected by the degree of roasting. Food Chem. 2011;129:9911000. https://doi.org/10.1016/j.foodchem.2011.05.059

34. Komes D, Belščak-Cvitanović A, Škrabal S, Vojvodić A, Bušić A. The influence of dried fruits enrichment on sensory properties of bitter and milk chocolates and bioactive content of their extracts affected by different solvents. LWT - Food Sci Technol. 2013;53:360-9.

https://doi.org/10.1016/j.lwt.2013.02.016

35. Papadopoulou A, Frazier RA. Characterization of protein-polyphenol interactions. Trends Food Sci Technol. 2004;15:186-90. https://doi.org/10.1016/j.tifs.2003.09.017

36. Tong LM, Sasaki S, McClements DJ, Decker EA. Mechanisms of the antioxidant activity of a high molecular weight fraction of whey. J Agric Food Chem. 2000;48:1473-8. https://doi.org/10.1021/jf991342v

37. Mazumder A, Neamati N, Sunder S, Schulz J, Pertz H, Eich E, Pommier Y. Curcumin analogs with altered potencies against HIV-1 integrase as probes for biochemical mechanisms of drug action. J Med Chem. 1997;40:3057-63. https://doi.org/10.1021/jm970190x

38. Amaral GP, de Carvalho NR, Barcelos RP, Dobrachinski F, de Lima Portella R, da Silva MH, et al. Protective action of ethanolic extract of Rosmarinus officinalis L. in gastric ulcer prevention induced by ethanol in rats. Food Chem Toxicol. 2013;55:48-55. https://doi.org/10.1016/j.fct.2012.12.038

39. Vallverdú-Queralt A, Regueiro J, Martínez-Huélamo M, Alvarenga JFR, Leal LN, Lamuela-Raventos RM. A comprehensive study on the phenolic profile of widely used culinary herbs and spices: Rosemary, thyme, oregano, cinnamon, cumin and bay. Food Chem. 2014;154:299-307. https://doi.org/10.1016/j.foodchem.2013.12.106

40. Morgan F, Gaborit P. The typical flavour of goat milk products: technological aspects. Int J Dairy Technol. 2001:54:38-40. https://doi.org/10.1046/j.1471-0307.2001.00006.x 